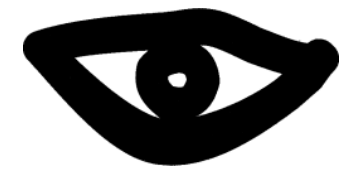

\title{
As consequências das avaliações externas em larga escala no trabalho docente
}

\author{
Edna Borges*, Virgínio Sá** \\ *Universidade Federal de Minas Gerais, Brasil **Universidade do Minho, Portugal
}

\begin{abstract}
Resumo
O Sistema Mineiro de Avaliação da Educação Pública (SIMAVE), criado no ano de 2000 no estado de Minas Gerais, Brasil, insere-se no processo de reforma do Estado implantado pelo governo brasileiro, a partir do início da década de 1990, com o objetivo de o reformar, reorganizar e modernizar. Este artigo apresenta resultados parciais de uma investigação mais ampla que procura conhecer e refletir sobre os significados atribuídos pelos docentes quanto à influência dos processos avaliativos externos em sua prática cotidiana.
\end{abstract}

Palavras chave: avaliação externa, educação básica, trabalho docente.

O SIMAVE foi criado no ano de 2000 como um mecanismo estratégico de planejamento da política educacional do estado de Minas Gerais, para a efetivação de políticas mais equitativas com o objetivo de melhorar a qualidade da educação. Apresenta como princípios a descentralização, participação, gestão consorciada, formação do professor, equidade, publicidade e independência. Insere-se no contexto da reforma do Estado, efetivada pelo governo brasileiro, na década de 1990 que, por sua vez, está alinhada com as transformações económicas, políticas e sociais que atingiram diversos países do mundo a partir da década de 1970.

A proposta desta comunicação é apresentar, de forma resumida, parte da pequisa de doutoramento sobre as consequências das avaliações externas na prática de docentes da rede pública estadual de Minas Gerais. A investigação apoiou-se em pesquisa bibliográfica, pesquisa documental e pesquisa de campo. Para a compreensão da construção do Sistema de Avaliação da Educação Básica (SAEB) no Brasil e do SIMAVE, foram consultados, entre outros, os seguintes autores: Gatti (2013), Freitas (2013), Horta Neto (2006), Brooke (2011), Vianna (2005).

\section{Avaliação, estado avaliador e qualidade da educação}

Para diversos autores, como Afonso (1998, 2005, 2012), Barroso, (2005), Lessard (2008), Lima (2011), Oliveira (1999, 2000), Sá (2009), Waiselfisz (1993) e Sousa e Arcas (2010), as reformas educacionais que se iniciaram em meados da década de 1980 , ocorrem no âmbito da redefinição do papel do Estado e das funções do poder central, dando origem a um novo Estado, muitas vezes denominado de "Estado Regulador", outras de "Estado Avaliador", "Estado Articulador", "Estado Mínimo" ou "Estado
Gestor". Este novo Estado implementará um novo modelo de regulação educativa, produto das novas articulações entre as demandas globais e as respostas locais que afetará substancialmente a gestão e organização do trabalho escolar, tendo nas avaliações externas do desempenho escolar dos estudantes o seu eixo central.

Ao abordar a avaliação sob o ponto de vista político e organizacional, Lima (2011, p. 73) destaca o seu processo de racionalização, identificando-a como avaliação científica ou neo-tayloriana. Essa lógica é denominada pelo autor de educação contábil, na qual a educação "é orientada para a performatividade competitiva, segundo o cânone gerencialista, com seus objetivos precisos e seus resultados rigorosamente quantificados."

Outro aspecto que vem sendo abordado na literatura sobre avaliação educacional é a sua associação com a prestação de contas e responsabilização (accountability). Segundo Afonso (2012), o conceito de accountability está enclausurado nas lógicas do pensamento único, neoconservador e neoliberal e indica "uma forma hierárquico-burocrática ou tecnocrática e gerencialista de prestação de contas (...)", gerando formas autoritárias de de responsabilização das instituições educacionais e dos individuos.

O autor avalia como sendo necessária a articulação da avaliação com a prestação de contas e a responsabilização, mas com outra configuração, "pressupondo relações e conexões mais abertas, problematizáveis e susceptíveis de se aperfeiçoarem ou reconstruírem", e que se legitimem em valores e princípios essenciais, como a cidadania crítica, o empowerment, o direito à informação e a transparência.

Ao discutir a relação entre avaliação e qualidade, Sá (2009) observa que a qualidade, como avaliação, tem sido vista como uma espécie de amuleto, capaz de sanar a crise que se abate sobre a educação. Contextualiza que o discurso da qualidade ganhou destaque no cenário educacional a partir de finais da década de 1980 e princípios da década de 1990, período em que a "agenda da democratização cede progressivamente lugar ao discurso da qualidade, entendendo-se esta na sua versão mercantil (Sá, 2009, p. 93).” O autor ressalta que não há nada de demoníaco no termo qualidade, mas que é importante "pôr a descoberto" os discursos hegemônicos que a veiculam (Idem, p. 94).

Segundo Sousa e Arcas (2010:187), as políticas de avaliação "podem conter possibilidades emancipadoras ou virem a servir à intensificação das desigualdades educacionais e sociais, seus fins e meios e os usos de seus resultados são reveladores do real significado que assumem no processo educacional". 


\section{O SIMAVE e o Programa de Avaliação da Rede Pública de Educação Básica (PROEB)}

Inicialmente composto apenas pelo Programa de Avaliação da Rede Pública de Educação Básica (PROEB), o SIMAVE ampliou-se e expandiu-se, com a criação do Programa de Avaliação da Aprendizagem $(\text { PAAE })^{1}$ e do Programa de Avaliação da Alfabetização (PROALFA), incluindo as redes de ensino dos 853 municípios de Minas Gerais.

O PROEB, foco da nossa pesquisa, nasceu com a regulamentação do SIMAVE, tendo como objetivo monitorar o desempenho dos alunos e das escolas do estado, por meio da aplicação sistemática de testes de avaliação dos níveis de proficiência e habilidades construídas pelos alunos e as escolas no processo educativo. Foi desenvolvido por meio de um acordo de cooperação técnica assinado com o Ministério da Educação Nacional, Ciência e Tecnologia, da França, e posteriormente com o Instituto Nacional de Estudos e Pesquisas Educacionais (INEP), do Ministério da Educação (Minas Gerais, 2002, p. 44).

Após algumas mudanças, o PROEB atualmente avalia as habilidades e competências desenvolvidas em Língua Portuguesa e Matemática por todos os alunos matriculados no $5^{\circ} \mathrm{e} 9^{\circ}$ anos do Ensino Fundamental e no $3^{\circ}$ ano do Ensino Médio, nas escolas públicas de Minas Gerais. Além dos testes, o PROEB inclui questionários para os alunos, com o objetivo de traçar o perfil socioeconômico e cultural, e questionários para professores e especialistas da escola. Além disso, são computados dados relativos às condições da escola e ao seu comportamento quanto à seletividade dos alunos (índice de evasão, repetência ou retenção).

Os documentos oficiais do PROEB indicam que a divulgação dos resultados por escola não tem como objetivo estabelecer uma classificação entre as mesmas, mas indicar os rumos a serem seguidos na política educacional de Minas, garantindo a equidade e a igualdade de oportunidades a todos os alunos da rede pública de educação básica em Minas Gerais (MINAS GERAIS, 2000, p. 28).

Importante descatar que a partir de 2002 foi implantado em Minas Gerais o Programa "Choque de Gestão", que buscou aplicar na administração pública um modelo inspirado no setor privado. $\mathrm{O}$ enxugamento da máquina, a bonificação de servidores de acordo com os resultados alcançados e a obsessão pela redução de despesas eram os pontos centrais. Uma das medidas do "Acordo de Resultados", no âmbito desse programa, foi a vinculação dos reajustes salariais dos docentes e os bônus salariais ao desempenho das escolas no SIMAVE.

\section{Os usos dos resultados das avaliações externas em larga escala}

A maioria das pesquisas sobre as consequências das avaliações de larga escala na educação está relacionada

\footnotetext{
${ }^{1}$ Mais informações sobre o PAAE e o PROALFA no endereço www.educacao.mg.gov.br
}

às experiências desenvolvidas nos Estados Unidos, a partir da década de 80 . O grau de pressão/indução que a autoridade educacional utiliza sobre as escolas, em função dos resultados das avaliações, pode variar, sendo comum rotular os níveis mais altos de higtstakes e os mais baixos de lowstakes (Brooke; Cunha, 2011). Na experiência americana, as escolas devem atingir metas estipuladas para todos os grupos étnicos e, caso elas não sejam atingidas, os alunos podem ser transferidos e a escola fechada.

Madaus, Russell e Higgins (2009), a partir de pesquisas empíricas, avaliam que os testes de alto impacto são paradoxais, na medida em que são políticas públicas bem intencionadas, mas com consequências negativas não intencionais. Constatam que, entre outras consequências, em função da pressão sobre os professores para melhorarem o desempenho dos alunos, os testes têm:

a) Influenciado as práticas de ensino, levando os professores a focar o trabalho nas disciplinas e habilidades que possibilitam a preparação dos alunos para as provas.

b) Afetado a forma como os professores trabalham, não levando em consideração a demografia da sala de aula como um fator importante para a compreensão do desempenho dos alunos.

c) Levado a um aumento da segregação dos alunos que estão nas pontas dos desempenhos - mais altos e mais baixos - e uma atenção maior àqueles que estão próximos da média, com mais probabilidade de ter sucesso nos testes.

d) Provocado um crescimento das taxas de abandono e da retenção no grau, em função da pressão exercida sobre os alunos.

e) Quando utilizados como indicadores para metas sociais e para prestação de contas eles podem ser corrompidos: preparação específica, deliberada dos alunos para a prova; rebaixamento dos níveis dos testes para melhorar artificialmente as notas dos estudantes e a ajuda dos professores aos alunos durante a realização dos exames.

No Brasil, com o avanço das avaliações educacionais de larga escala em todo o país, começaram a surgir pesquisas que buscam analisar a origem, pressupostos e implicações das avaliações externas em larga escala.

Bonamino e Sousa (2012) discutem os riscos das avaliações padronizadas que referenciam políticas de responsabilização para os educadores, reforçarem a preocupação dos diretores e professores com a preparação dos alunos para os testes, levando a um estreitamento do currículo escolar, restringindo-o aos conteúdos que são cobrados nos testes. Por outro lado, as autoras apontam o potencial dessas avaliações na indução de discussões sobre o currículo escolar, em termos de habilidades básicas que devem ser dominadas por todos os alunos em Língua Portuguesa e Matemática.

A pesquisa realizada por Sousa e Oliveira (2010), que analisa sistemas de avaliação implementados nos estados da Bahia, Ceará, Minas Gerais, Paraná e São Paulo, conclui que houve melhoras significativas no 
desenho técnico dos instrumentos e na confiabilidade dos resultados. Observam, entretanto, que são tênues os usos dos resultados das avaliações pelas Secretarias de Educação e que algumas apresentam iniciativas para tornar o uso dos resultados das avaliações mais efetivo, como o de tentar articular a avaliação externa à auto avaliação, com a perspectiva de avaliar todas as instâncias do sistema escolar e, em outra direção, iniciativas de associar os resultados das avaliações a incentivos financeiros para professores e funcionários.

A pesquisa de Brooke (2011) aponta a existência de uma diversificação e aprimoramento das metodologias para avaliação da educação no Brasil, assim como na forma que os seus resultados são utilizados na tomada de decisões pelos gestores dos sistemas de ensino.

Segundo Brooke (2011), na maioria dos casos essas políticas podem ser entendidas como contribuições importantes para a melhora da qualidade da educação, mas em outros, são utilizadas "de forma desavisada" como, por exemplo, um dos componentes da política da avaliação docente e para certificação de alunos e escolas, independente do histórico ou da realidade local. Salienta que, no contexto brasileiro, as políticas de responsabilização formuladas em termos de incentivos salariais podem ser inócuas no que se refere ao objetivo de melhorar a qualidade da educação.

A utilização dos resultados das avaliações para as políticas de incentivos salariais e como componente da política de avaliação docente são as duas categorias mais polêmicas. Estudos como o de Veloso (2009) defendem que a melhoria da qualidade da educação passa necessariamente por três mecanismos institucionais: responsabilização dos atores educacionais pelos resultados da educação por meio de um sistema de bônus para incentivar o desempenho dos professores; competição entre as escolas por recursos públicos e descentralização e autonomia das escolas mediante um contrato entre governo e escolas, no qual as mesmas se comprometem com o alcance de metas de desempenho previamente traçadas.

Por outro lado, há uma reação contrária muito forte a esta visão da parte de sindicatos e associações. Uma reação significativa foi o Movimento Contra Testes de Alto Impacto criado em 2010, durante a $33^{\mathrm{a}}$ Reunião Anual da Associação Nacional de Pós-Graduação e Pesquisa em Educação, com o lançamento do documento "Por uma responsabilização participativa e democrática na educação". Nesse documento ressalta-se que o uso das avaliações como ferramenta de políticas públicas, "requer a consciência de seus limites, pois a redução da concepção de qualidade da educação àquilo que pode ser verificado nas medidas pode induzir ao empobrecimento da compreensão do fenômeno educacional e ao empobrecimento da educação que pretendemos universalizar como direito de todos".

\section{A pesquisa}

Os dados empíricos aqui mobilizados, foram recolhidos por meio de questionários encaminhados de forma on-line, aos professores que participaram do "III Seminário Prevenção da violência nas escolas e promoção de uma cultura de paz: buscando caminhos", organizado pela Escola de Formação e Desenvolvimento Profissional de Educadores (MAGISTRA/SEEMG), no período de 10 a 14 de novembro/2014. Para este seminário inscreveram-se 594 educadores da educação básica, de todas as 47 Superintendências Regionais de Ensino (SRE) do estado de Minas Gerais, sendo: 83 representantes das SRE, 317 professores, 78 especialistas em educação básica, 85 diretores de escolas, 26 vice diretores de escolas, 03 coordenadores do programa Reinventando o Ensino Médio, 01 secretário escolar e 01 analista educacional. Dos 317 professores que receberam o questionário, 100 fizeram a devolução.

\section{Resultados e discussão}

Os dados coletados foram organizados em dois grandes eixos: percepção geral dos professores sobre as avaliações externas; ações desenvolvidadas pela escola com a participação dos professores, ou pelos próprios professores, a partir dos resultados do PROEB

Eixo I - Percepção geral dos professores sobre as avaliações externas

As respostas da grande maioria dos professores respondentes permitem afirmar que, em boa medida, as avaliações externas têm grande penetração nas escolas: 98,2\% conhecem o PROEB; sabem os resultados da escola onde trabalha $(87,4 \%)$, localizam a posição da escola em relação à média do PROEB do estado $(90 \%)$ e sabem analisar a escala de proficiência $(81,1 \%)$.

A maioria dos professores $(74,7)$ considera que as diferenças entre as escolas nas avaliações são mais um reflexo das características socioculturais e econômicas dos alunos do que da efetividade do trabalho escolar. Além disso, 69,3\% acreditam que a diferença de desempenho da escola no PROEB, de um ano para outro, reflete mais as mudanças nas características dos alunos do que mudanças efetivas na escola. Os professores (91\%) não acreditam que as avaliações externas provoquem abandono escolar.

Após a divulgação dos resultados das avaliações os professores identificam que há uma responsabilização da escola pelos resultados apresentados; principalmente pelo ranqueamento das escolas.

Mais da metade considera que os resultados que os alunos apresentam no PROEB são semelhantes aos resultados apresentados nas avaliações de aprendizagem, elaboradas pelos professores, sendo que $71,1 \%$ consideram que as avaliações externas são uma boa estratégia para a mensuração do que os estudantes aprenderam.

Os professores $(80 \%)$ possuem alta expectativa com relação aos resultados dos estudantes nas avaliações externas e $63 \%$ acreditam que as mesmas motivam os alunos a estudarem mais, enquanto $37 \%$ discordam totalmente ou parcialmente disto. A auto-estima dos alunos da escola é considerada por $74,7 \%$ dos professores como um elemento que favorece o bom desempenho nos testes e 78,4\% avaliam que os alunos acreditam que quanto mais se esforçarem melhor se sairão nas avaliações. Quanto à ansiedade dos alunos nos 
dias dos testes, 44\% acreditam que eles ficam ansiosos e $45 \%$ acreditam que não. Essa relação se mantem próxima também na questão que diz respeito à interferência da ansiedade dos alunos no resultado da avaliação.

Os professores $(81 \%)$ discordam da afirmação de que criam estratégias de melhorar os resultados nas avaliações externas sem realmente melhorar o aprendizado dos estudantes e $91 \%$ acreditam que os alunos não colam durante os testes. A maioria (74\%) afirma que nunca viu nenhum colega de trabalho utilizar estratégias que possam melhorar as notas dos alunos, como dar alguma dica de resposta para os estudantes ou dar mais tempo do que o permitido para o aluno fazer o teste. Porém, $15,3 \%$ dos respondentes afirmam terem visto colegas de profissão darem mais tempo do que o permitido para a prova e $8 \%$ viram colegas darem dicas de respostas.

Os professores sentem-se pressionados para melhorar o desempenho da escola nas avaliações externas pelas SRE $(77,4 \%)$; pelo diretor $(59,4 \%)$ e pela comunicação social $(56,7 \%)$. Na percepção dos professores $(17,1 \%)$ os pais são os que menos pressionam.

A opinião dos professores é dividida quanto à percepção do comportamento dos alunos em relação às avaliações: $57,6 \%$ discordam da afirmação de que os estudantes se sentem pressionados para melhorarem seus resultados nas avaliações externas, enquanto 42,3\% concordam.

Eixo II - Ações desenvolvidadas pela escola com a participação dos professores, ou pelos próprios professores, a partir dos resultados do PROEB

A maioria dos professores $(66,7 \%)$ considera que as avaliações externas influenciam a sua prática de ensino e as suas ações, mas $63,9 \%$ não acreditam que elas induzam os professores a adotarem posturas pedagógicas que sejam contraditórias com aquelas nas quais acreditam.

Ao serem indagados se as avaliações externas em larga escala têm influenciado a organização e o desenvolvimento do trabalho da escola, bem como o trabalho dos docentes, mais de $80 \%$ responderam afirmativamente. No entanto, ao serem apresentadas algumas possibilidades de alterações na dinâmica da escola, 63\% responderam que não houve alteração; somente $29,7 \%$ consideram que houve um aumento de tempo destinado às disciplinas avaliadas (Língua Portuguesa e Matemática).

Após a divulgação dos resultados das avaliações externas os professores participam de reuniões com as equipes pedagógicas das SRE e especialistas para avaliar e discutir os resultados dessas avaliações e, em seguida, elaborarem o Plano de Intervenção Pedagógica da Escola (PIP). Outra reunião da qual os professores participam é com a comunidade escolar, especialmente com os pais e responsáveis, para divulgar os resultados da escola, discutir e aprovar o PIP.

A partir dos questionário não é possível identificar se está ou não ocorrendo um estreitamento curricular, pois as respostas a algumas questões desse campo são um pouco contraditórias. Os professores respondentes consideram que a matriz de referência do PROEB está alinhada como os Conteúdos Básicos Comuns (CBC) do
Estado e $85,5 \%$ acreditam que se trabalharem bem com os CBC os estudantes apresentarão melhor desempenho nas avaliações externas. Isto demonstra que há uma compreensão de que a proposta curricular é mais ampla do que a matriz de referência das avaliações. Para 52,2\% dos professores a pressão existente para a obtenção de notas altas nas avaliações não tem levado os educadores a restringir o ensino somente às questões que caem no teste, enquanto que $46,8 \%$ acreditam que pode levar à restrição do que ensinar. Apenas 2,7\% consideram que ocorreu diminuição no tempo destinada às atividades de enriquecimento curricular.

Consideramos como positivo a percepção dos professores $(84,7 \%)$ de que as avaliações externas trouxeram necessidade de maior atenção ao processo de ensino-aprendizagem. Com relação às mudanças nas práticas de avaliação da aprendizagem, 83,7\% responderam que as avaliações que elaboram e aplicam aos seus alunos têm o mesmo formato das avaliações externas e os mesmos conteúdos $(82,9 \%)$.

Como forma de preparar os alunos para as avaliações externas os professores responderam, por ordem decrescente, que encorajam os alunos para se esforçarem e se preparem; utilizam itens similares aos dos testes e utilizam os materiais que são disponibilizados pela Secretaria de Educação. Ao serem questionados sobre as estratégias que utilizam para a preparação dos alunos para as avaliações externas, $88,3 \%$ responderam que apostam e motivam todos os alunos, não fazendo trabalho diferenciado com grupos específicos e somente $5,4 \%$ apostam nos alunos que estão com nível de proficiência acima da média.

Para mobilizar os alunos para as avaliações, a estratégia mais utilizada pelos professores $(56,2 \%)$ é discutir com eles sobre a importância para a escola de que eles se saiam bem nessas avaliações; realizarem palestras ou assembleias para motivá-los (24,4\%) e reconhecer publicamente os estudantes que tiveram um bom desempenho (10,6\%).

A maioria dos professores $(67,6 \%)$ respondeu que o trabalho que realiza durante o ano letivo possibilita que os alunos estejam preparados para as avaliações externas.

No âmbito da escola as ações mais presentes nas respostas dos professores foram, por ordem decrescente, avaliar o progresso dos estudantes; avaliar a efetividade do trabalho do docente; selecionar materiais para as aulas; planejar o currículo; organizar grupos de estudos de alunos fora da clase, conforme suas dificuldades e dar retorno para os estudantes.

\section{Considerações Finais}

A pesquisa constata que, na perspetiva dos inquiridos, as avaliações externas têm grande penetração nas escolas públicas estaduais de Minas Gerais e que os professores afirmam ter uma boa compressão sobre elas, em especial no caso do PROEB.

Apesar da intenção declarada pela SEE de não estabelecer classificação das escolas com a publicação dos resultados das avaliações, os professores consideram que ocorre um ranqueamento das mesmas e sentem-se pressionados pelo gestores para melhorar o desempenho 
dos alunos. Descata-se que uma das estratégias que os professores utilizam para melhorar o desempenho dos alunos é utilizar o formato e conteúdos das avaliações externas na avaliação da prendizagem. Considera-se esse fato preocupante, uma vez que os testes não abarcam toda a proposta curricular das escolas.

A discussão dos resultados das avaliações com a comunidade e a construção do Plano de Intervenção Pedagógica é um aspecto positivo, no entanto parecem tênues as alterações que as avaliações têm provocado na prática dos professores e considera-se que as entrevistas poderão trazer mais elementos para a sua compreensão.

É importante ressaltar que a avaliação não pode constituir-se um fim em si mesma. Seu objetivo deve ser o de fornecer subsidios para que os sujeitos que atuam nas escolas possam rever suas práticas e, assim, melhorar a equidade e a qualidade da educação.

\section{Referências}

AFONSO A.J. (1998). Políticas Educativas $e$ Avaliação Educacional: para uma análise sociológica da reforma educativa em Portugal (1985-1995). Universidade do Minho, Instituto de Educação e Psicologia. Centro de Estudos em Educação e Psicologia.

AFONSO, A.J. (2005). Avaliação Educacional: regulação e emancipação: para uma sociologia das políticas avaliativas contemporâneas. 3. ed. São Paulo: Cortez.

AFONSO. A.J. (2012) Para uma conceituação alternativa de accountability em educação. Educação \& Sociedade. Campinas. V. 33, n. 119, p.471-484, abr.-jun.

BARROSO, J. (2005). O estado, a educação e a regulação das políticas públicas. Educação \& Sociedade. Campinas, vol. 26, n.92, p. 725-751, Especial, out.

BONAMINO, A.C.D \& SOUSA, S. Z. (2012) Três gerações de avaliação da educação básica no Brasil: interfaces com o currículo da/na escola. Educação $e$ Pesquisa. Vol. 38, n. 2, p.373-388.

BROOKE N. (2011) (coord). A avaliação externa como instrumento da gestão educacional nos estados. Relatório Final. Grupo de Avaliação e Medidas Educacionais. Belo Horizonte.

BROOKE, N. \& CUNHA, M.A. (2011). A avaliação externa como instrumento da gestão educacional nos estados. Estudos \& Pesquisas Educacionais. $\mathrm{N}^{\mathrm{o}} 2$, Fundação Victor Civita. São Paulo.

FREITAS, L.C. (2013). Caminhos da Avaliação de Sistemas Educacionais no Brasil: o embate entre a cultura da auditoria e a cultura da avaliação. Ciclo de Debates. Vinte e cinco anos de avaliação de sistemas educacionais no Brasil. Origem e pressupostos. Florianópolis: Insular.

GATTI, B.A. (2013). Possibilidades e Fundnamentos de Avaliações em Larga Escala: Primórdios e Perspectivas Contemporâneas. BAUER, A, GATTI, B.A $\&$ TAVARES, M.A. (orgs). Ciclo de Debates. Vinte e cinco anos de avaliação de sistemas educacionais no Brasil. Origem e pressupostos. Florianópolis: Insular.

HORTA NETO, J.L. (2006) Avaliação externa: a utilização dos resultados do SAEB 2003 na gestão do sistema público de ensino fundamental no Distrito Federal. (Mestrado em Educação). Universidade de Brasília.

LESSARD, C. (2008). Pesquisas e Políticas Educativas: uma interface problemática. Colóquio $e$ pesquisa e políticas Educativas: uma interface necessária. Belo Horizonte. Brasil. Tradução; Ceres Leite Prado (mimeo).

LIMA, L.C. (2011) Avaliação, competitividade e hiperburocracia. ALVES, M.P. \& KETELE, Jean-Marie (orgs). Do currículo à avaliação, da avaliação ao currículo. Porto Editora, Porto.

MADAUS, G., RUSSELL, M. \& HIGGINS, J.. (2009). The paradoxes of high stakes testing. How they affect students, their parents, teachers, principals, schools, and society.Information Age.

MINAS GERAIS. Escola Sagarana: educação para a vida com dignidade e esperança. FREITAS, J. E. (org). (1999). Coleção Lições de Minas, V. II. Belo Horizonte:SEE/MG.

(2000). Resolução SEE $n^{o}$ 104, de 14 de julho de 2000. Belo Horizonte.

OLIVEIRA, D. A. (1999). Política e Trabalho na Escola: Administração dos sistemas públicos de educação básica. Belo Horizonte. Autêntica. (2000). Educação Básica: gestão do trabalho e da pobreza. Petrópolis. Rio de Janeiro. Vozes

SÁ, V. (2009). A (auto)avaliação das escolas; "virtudes" e "efeitos" colaterais". Ensaio: avaliação e Políticas Públicas em Educação. Rio de Janeiro, v. 17, n. 62, p. 87-108, jan./mar.

SOUSA, S.Z.\& ARCAS, P.H. (2010). Implicações da Avaliação em Larga Escala no Currículo: revelações das escolas estaduais de São Paulo: Educação: Teoria e Prática. São Paulo, v. 20, n. 35, p.181-199, jul./dez.

VIANNA, H.M. (2005). Fundamentos de um programa de avaliação educacional. Brasília: Liber Livro.

VELOSO, F., PESSÔA, S., HENRIQUE, R. \& GIAMBIAGI, F. (orgs). (2009). Educação Básica no Brasil: Construindo o país o futuro. Rio de Janeiro: Elsevier, 2009.

WAISELFISZ, J. (1993). Sistema de Avaliação do desempenho escolar e políticas públicas. Ensaio, vol.1, out $/$ dez. 